\title{
OBSERVAÇÕES SOBRE INTERDISCURSO
}

Sírio Possenti*

0 ob diversos nomes - polifonia, dialogismo, heterogeneidade, intertextualidade - cada um implicando algum viés específico, como se sabe, o interdiscurso reina soberano há algum tempo. Schneider chega a dizer, a propósito de um tema bem específico e à primeira vista não relacionado a essa problemática, que "sob o nome sapiente de intertextualidade, [até] o plágio voltou a ser alguma coisa que não é mais uma fatalidade, mas sim um procedimento de escritura como outro qualquer, às vezes reivindicado como único" (Schneider, 1985, p. 59).

Tamanha unanimidade poderia fazer pensar que ou o interdiscurso nem deveria mais ser um tema (pelo menos, não na forma de problema) ou que se trataria apenas de detalhar o quebra-cabeças, especificando cada vez mais minuciosamente um conjunto de aspectos dos discursos, que se fundam nessa categoria ou que a transformaram em um monumento teórico e empírico.

Mas a Análise do Discurso (AD) não funciona como (supomos que funciona) a física ou mesmo a gramática gerativa, ou seja, a partir da última versão da teoria, porque ela teria superado as anteriores. Isso significa que não há propriamente, no campo da $\mathrm{AD}$, questões vencidas. E por isso sempre haveria o que dizer também sobre interdiscurso.

* Universidade Estadual de Campinas. 
Por exemplo, há algum tempo, Fiorin (1994) propôs que se distinguisse intertextualidade de interdiscurividade (a segunda implica a primeira, mas a relação inversa não é necessariamente verdadeira). Creio que se trata, de maneira geral, de uma distinção importante, embora possa ser problematizada, se se mostrar convincentemente que o texto é mais que a materialidade lingüística, fazendo parte da própria discursividade, na medida em que um discurso, em decorrência de sua semântica global, parece preferir certos gêneros a outros, como é o caso do jansenismo e do humanismo devoto, segundo a análise de Maingueneau (1984), ou introduzir citações segundo estratégias diversas, segundo se trata de uma ou de outra fonte (Brunelli (2001) mostra que o discurso da auto-ajuda cita fontes como a Bíblia só na forma de discurso direto, mas cita indiferentemente em discurso direto e indireto textos menos "altos"). Isso sem contar a problemática do ethos, que é, evidentemente, discursiva, mas que configura os textos de certa forma.

Neste trabalho, desejo apenas comentar certos aspectos das definições - e de algumas de suas conseqüências - de interdiscurso em Pêcheux (1975) e em Courtine (1981), de um lado, e em Maingueneau, de outro.

Vejamos o que parece consensual. Em Charaudeau e Maingueneau (2002), o verbete "interdiscurso" é apresentado com um sentido restritivo (conjunto de discursos do mesmo campo que mantêm relações de delimitação recíproca uns com os outros) e com um sentido amplo (conjunto das unidades discursivas com as quais um discurso entra em relação explícita ou implícita). No mesmo verbete, um subitem refere-se ao "primado do interdiscurso", uma tese da escola francesa, tanto em teoria quanto em análise. Tal primado implica que uma FD produz o assujeitamento do sujeito na medida em que cada FD é dominada pelo interdiscurso e exclui que sejam colocadas em contraste FDs consideradas independentemente umas das outras.

Vale a pena reter, desse dicionário, o fato de que propõe definições mais restritas e mais amplas.

\section{Em Pêcheux}

Uma das teses de Pêcheux (1975, p. 162) é que

...toda formação discursiva dissimula, pela transparência de sentido que nela se constitui, sua dependência com relação ao 
"todo complexo com dominante" das formações discursivas, intrincado no complexo das formações ideológicas...

O que mais importa destacar dessa formulação é a afirmação da dependência da FD em relação ao todo complexo com dominante (a questão da dissimulação é relevante, mas aqui deve ficar de lado). $\mathrm{O}$ que se especifica melhor em outra passagem, na qual o autor propõe "chamar interdiscurso a esse 'todo complexo com dominante' das formações discursivas, esclarecendo que também ele é submetido à lei de desigualdade-contradição-subordinação que (...) caracteriza o complexo das formações ideológicas" (Pêcheux, 1975). Nessa passagem, o que mais importa destacar é a caracterização do todo complexo com dominante como interdiscurso e a insistência em dizer que uma FD depende dele.

Ambas as formulações parecem plenamente aceitáveis, pelo menos em relação ao que foi destacado (quero dizer que alguém poderia aceitar essa tese sem considerar, ou mesmo não aceitando, a tese da dissimulação). Mas, pelo menos para mim (talvez um mau sujeito...), à medida que isso se detalha, que outras categorias se definem, nem tudo continua tão claro.

Refiro-me especificamente ao papel crucial do pré-construído. Através deste conceito, uma interessantíssima reformulação da noção de pressuposição, a $\mathrm{AD}$ pretende dar conta do fato de que algo sempre fala antes e alhures. O préconstruído "corresponde ao 'sempre-já-aí' da interpelação ideológica que forneceimpõe a 'realidade' e seu 'sentido' sob a forma de universalidade ('o mundo das coisas')" (p. 164). Em termos, digamos, filosóficos, o que está em questão é a posição segundo a qual os sujeitos falam a partir do já dito - e isso é exatamente o que o interdiscurso lhes põe à disposição e/ou lhes impõe.

Uma interpretação "favorável" desta passagem não veria nela problema algum. Mas, a meu ver, às custas de duas restrições: a) universalidade deve significar efeito de universalidade para uma certa FD, ou para um sujeito em sua relação com uma certa $\mathrm{FD}$; b) nem todos os pré-construídos estão à disposição, ou, alternativamente, nem todos são impostos a cada sujeito, mas apenas aqueles que ele pode/deve dizer.

Se for assim, o pré-construído não é da ordem do interdiscurso (não releva dele), a não ser naquilo que é por demais óbvio, ou seja, sem a necessária relevância. Ou é relevante apenas se se entender por interdiscurso o que veio antes (mas então algo fala antes, mas não necessariamente alhures...). O préconstruído parece ser da ordem de cada FD ou daquelas com as quais cada uma 
está em posição de franca aliança. Isso é ainda mais claro quando pré-construídos se articulam na forma de discurso transverso, dado que tanto a equivalência quanto a implicação só se dão - só funcionam - no interior de FDs definidas (científicas ou ideológicas) - isto é, jamais em uma FD antagonista. Em outras palavras, o "todo complexo" põe à disposição um conjunto $\mathrm{X}$ de pré-construídos, mas, para cada sujeito, ou para cada "comunidade" de sujeitos (ou, ainda, para cada FD), só são selecionáveis os pré-construídos aceitáveis para essa FD. Dizendo de outro modo, só estão disponíveis, para cada FD, os pré-construídos cujo sentido é evidente para essa FD.

Seja o seguinte exemplo: para um enunciador tucano/governista/liberal, que disse/ouviu durante vários anos que o governo $\mathrm{FHC}$ foi bem sucedido, que conseguiu estabilizar a economia, que organizou uma base parlamentar sólida, que foi ouvido no exterior como estadista etc., a expressão o sucesso... (do governo FHC) será pura evidência. Mas, para um oposicionista (para um sujeito dominado por outra FD), trata-se de uma seqüência não enunciável. Ou que ele só poderá proferir pondo-a à distância - marcando-a de alguma forma como sendo do Outro (pretenso sucesso, sucesso entre aspas, o que eles chamam de sucesso etc.). De fato, o que "pertence" a uma FD ou é retomado, afirmado, ou, alternativamente, denegado. Mas o que pertence a outra FD, mesmo fazendo parte do interdiscurso (o que é óbvio, dada a definição), só pode ser recusado, ironizado, parodiado, tornado simulacro.

O que estou querendo dizer é que não parece satisfatório definir interdiscurso como o todo complexo com dominante, a não ser que a expressão seja tomada restritivamente. Mas, se for esse o caso, seria mais proveitoso, como em uma das intervenções de Courtine (1981, Introdução, nota 3), considerálo como o exterior específico que domina ${ }^{1}$ uma FD - seja este exterior a uma outra FD determinada, ou um conjunto delas, com a qual, ou com as quais, uma relação específica e relevante se mantém.

O interdiscurso, como definido por Pêcheux, lembra bem a noção de universo de discurso, como definido por Maingueneau (ver abaixo). Reconhecer sua existência é, por um lado, uma obrigação, dado o quadro (é uma lapalissada). O conceito teoriza o "fato" de que um discurso não nasce de um retorno às próprias coisas, mas de um trabalho sobre outros discursos (Maingueneau, 1987, p. 120), tese que, é bem verdade que na forma de tateios, é ainda mais radicalmente defendida - ou, melhor dizendo, mostrada - por Scnheider (1985): "tudo já foi dito" é seu mote fundamental.

1 Mas penso que o fenômeno pode ocorrer mesmo sendo uma FD dominante, em cujo interdiscurso se encontre alguma FD "dominada", como é o caso da FD católica no caso analisado por Courtine (1981). 
Outro aspecto da tese de Pêcheux, segundo a qual é o interdiscurso que assujeita, ${ }^{2}$ e que dispõe materiais para uma $\mathrm{FD}$, sem especificação ulterior, parece um equívoco. Essa concepção é, talvez, o correlato da noção de "ideologia em geral", de Althusser. A despeito desse traço de coerência, a noção continua parecendo, pelo menos operacionalmente, problemática. Diria que é mais adequado propor que o que assujeita - se a tese for aceita - é uma certa FD. O que pode ficar mais claro em outras passagens da mesma obra, como quando Pêcheux trata de uma questão específica, a da "forma-sujeito na apropriação subjetiva dos conhecimentos..." (1975, p. 213 et seq.). Aqui, a meu ver, aparecem outras brechas nessa concepção.

Segundo Pêcheux, tal apropriação se opera segundo três modalidades, das quais importa aqui comentar a segunda, ${ }^{3}$ a separação, caso que ele chama de discurso do "mau sujeito", que ocorre quando

...o sujeito da enunciação "se volta" contra o sujeito universal por meio de uma "tomada de posição" que consiste em uma separação (distanciamento, dúvida, questionamento, contestação, revolta...) com respeito ao que o "sujeito universal" lhe "dá a pensar".

Tratar-se-ia, para Pêcheux, de luta contra a evidência ideológica, sobre o terreno dessa evidência, luta afetada pela negação, e que apresenta traços lingüísticos (aquilo que você chama crise do petróleo, suas ciências sociais...). Em suma, o mau sujeito se contra-identifica com a FD que lhe é imposta pelo "interdiscurso" como determinação exterior de sua interioridade subjetiva... ${ }^{4}$

Posso estar equivocado, mas não me convence a idéia de que uma FD seja imposta ao sujeito pelo interdiscurso, mesmo que essa palavra, no texto de Pêcheux, venha entre aspas. ${ }^{5}$ Em outros termos, seus próprios exemplos, mesmo

2 Às vezes, diz-se que o que assujeita o sujeito é uma FD...

3 A primeira e a terceira modalidades não interessam aqui diretamente, na medida em que a questão do interdiscurso é menos pertinente.

4 Seria extremamente interessante analisar os termos que, neste trecho de Pêcheux, estão entre aspas, porque esse procedimento de escritura parece desmentir o que vem sendo dito. O que, a meu ver, carrega água para meu moinho, no caso.

5 Faz falta uma teoria e uma análise do(s) processo(s) de assujeitamento, análogas aos diversos dispositivos de produção de subjetividade descritos por Foucault. 
brevíssimos, indicam que se trata da recusa de um discurso por parte de um "sujeito da enunciação", pouco importando - ou importando menos - se é o caso de um processo de contra-identificação (de um sujeito que se "rebela" contra uma FD que até então o dominava) ou de um processo mais banal, o da confrontação de um discurso com outro discurso - por exemplo, em um debate. Ou seja, trata-se, em qualquer caso, de serem enunciados, nas formas lingüísticas típicas dos préconstruídos, elementos que pertencem não ao interdiscurso, eu diria, mas a discursos específicos, em relação aos quais, de alguma forma, o sujeito está em franca oposição - independentemente, repito, de tratar-se de um caso de rebeldia ou de uma outra posição já sólida. E é isso que as marcas lingüísticas indicam.

Voltando a uma afirmação anterior: creio ser mais operacional a concepção de interdiscurso como exterior específico, embora ela talvez não recubra todas as possibilidades, especialmente as que dizem respeito ao esquecimento número $1 .^{6}$

Enfim, parece mais adequado propor que, para cada FD, há um conjunto de pré-construídos (discursos transversos ${ }^{7}$ etc.) no interdiscurso, aos quais um sujeito pode ou deve recorrer. Mas ele não pode recorrer a todos, como deveria ser óbvio. Dizer que é o interdiscurso que provê tais materiais é inócuo - a não ser talvez para combater "em geral" a tese da originalidade. Aqui, vale talvez uma analogia com as noções de intertextualidade interna (com a memória discursiva de cada FD) e de intertextualidade externa (aquilo que é da memória discursiva de outras FD com as quais as relações de uma FD não são de antagonismo). ${ }^{8}$

6 O sujeito não pode se encontrar no exterior da FD que o domina - o que remete ao exterior que determina a FD em questão (p. 173).

7 Quando, após sua eleição, Lula lançou o programa "Fome Zero", surgiu imediatamente uma reação na forma do discurso da "subalimentação", assumido, na ocasião, por um especialista universitário, com a pretensão de negar o discurso da fome. O presidente Fernando Henrique Cardoso, com o mesmo objetivo, mas com seu típico ethos tucano de superioridade (ver Miqueletti, 2002), disse que o que há é "subnutrição". Ora, trata-se do mesmo discurso, cujo outro é o discurso da fome, já que "subalimentação" mantém com "subnutrição" uma relação de causa e efeito - uma das modalidades de discurso transverso.

8 Ver Maingueneau (1984, p. 83-86). 


\section{Em Courtine}

Quando um estudioso do discurso se põe a analisar um corpus, tendo incorporado uma teoria do interdiscurso, o que ele faz? Analisa um discurso que se confronta com outro (e não com todos os outros). O melhor exemplo, para o que aqui importa, talvez seja o de Courtine (1981, isto é, Courtine antes da queda). O que ele revela talvez se deva em parte ao acaso, ou seja, ao fato de que analisa um discurso específico, o discurso comunista dirigido aos cristãos. Uma das características do trabalho foi revelar que não se pode (isto é, não vale a pena) analisar corpora sincrônicos - o que produz efeitos na noção de interdiscurso. Partindo de um enunciado como em (1), assinala que ele provém de uma seqüência discursiva que responde a CPs determinadas (é extraída de uma entrevista do então Secretário Geral Adjunto do P. C. F. ao jornal la Croix). Assim, pode-se relacioná-lo a um sujeito enunciador, que enuncia numa situação de enunciação determinada.

(1) Nossa política em relação aos cristãos não tem absolutamente nada de uma tática de circunstância, é uma política de princípio.

Mas esse enunciado estabelece laços com formulações que se podem descobrir no processo discursivo inerente à FD que o domina, a FD "comunista". Ou seja, existe igualmente numa rede interdiscursiva,${ }^{9}$ ou vertical, de formulações, tais como (2)-(9):

(2) De Lille, um pai de família, católico praticante, escreveu em julho de 36 que ele havia atribuído pouca importância ao primeiro apelo, que se podia ser tentado a crer que era ditado pelo interesse eleitoral. Ele não hesitou em nos falar de sua concordância e em nos encorajar, constatando em seguida nossa perseverança inflexivel. (M. Thorez, out. 1937)

9 Não fica muito claro se essa rede é interdiscursiva porque é sempre já "polêmica" ou porque é anterior ao acontecimento que é o pronunciamento de Marchais. Nada impede que seja por ambas as razões. 
(3) Temos ouvido contra nós a crítica, talvez pouco original, de manobrar, de empregar ardis, de agir com duplicidade. (M. Thorez, out. 1937)

(4) E se, hoje, confirmamos nossa posição de 1937, é que não se tratava, então, como alguns pretendem, de um ardil, de uma tática ocasional, mas de uma posição política perfeitamente de acordo como nossa doutrina: o marxismo-leninismo. (W. Rochet, 13 dez. 1944)

(5a) Para nós, a união não é uma tática ocasional, uma manobra ligada à conjuntura.

(5b) a luta pela união constitui uma constante, um princípio da política de nosso partido.

(5c) Nosso partido hoje empenhou-se com paixão e paciência em unir os trabalhadores, em agrupar em torno deles todas as vítimas do poder do dinheiro, todas as forças vivas da nação.

(6) Propomos às diversas camadas sociais que se unam, não na confusão, mas sobre uma base precisa. (XXI Congresso do PCF, 24 out. 1974)

(7) Os cristãos verificam cada vez mais que a cooperação, a luta comum que nós lhes propomos não é uma armadilha, mas uma démarche de princípio. (Princípios da política do PCF, out. 1975)

(8) Dizer isso é sublinhar o quanto a política de união é para nós uma política de princípio. (XXII Congresso do PCF, 4 fev. 1976)

(9) Não, não é por tática momentânea e na confusão ideológica que nós procuramos apaixonadamente fazer com que se encontrem lado a lado todos os que querem a libertação do homem - os comunistas porque é seu ideal socialista e os cristãos porque é seu ideal evangélico. (G. Marchais, 10 jun. 1976)

No entanto, o enunciado (1), diz Courtine, não se limita ao conjunto (2)(9) das formulações pertencentes à FD comunista, porque elas próprias só têm existência discursiva na contradição que as opõe ao conjunto das formulações (10)-(16), produzidas em CP heterogêneas às suas, a partir de posições de classe antagonistas:

(10) O comunismo é intrinsecamente perverso e não se pode admitir em nenhum terreno a colaboração com ele. (Pio XI, 19 mar. 1937)

(11) La Voix (de Thorez) se fez inutilmente tão ternamente premente como a do camponês que chama sua ninhada: "Pipipipipipi". Eu me dizia: "Não, é impossível que eles avancem!” (F. Mauriac, le Figaro, 18 abr. 1937) 
(12) Os cristãos se deixam prender na armadilha de uma filosofia vulgar da história. (R. Aron, le Grand Schisme)

(13) O católico não pode continuar nem ingênuo, nem abandonado diante da sedução discreta, da impregnação lenta ou da solicitação organizada do comunismo de hoje. (Monsenhor Fauchet, bispo de Troyes, fev. 1976)

(14) Os católicos são solicitados, numerosos são os que se deixam levar. (J. Boudais, le Figaro, 10 jun. 1976)

(15) Haverá uma ninhada católica para depenar? (Y. Levai, Europe 1, 11 jun. 1976)

(16) E mesmo se Marchais abjurasse sua fé, não seria um desses ardis que aconselhava precisamente Lênin? ( Senchet, l'Aurore, 11 jun. 1976)

Uma fórmula como (17) poderia condensar de maneira aproximativa esse conjunto de enunciados:

(17) “A união com os cristãos não é um ardil, é um princípio da política dos comunistas" versus "A política dos comunistas é uma armadilha na qual os cristãos não devem deixar-se prender".

Vejamos o que diz Courtine, depois da apresentação de suas evidências empíricas:

Se uma FD dada não é isolável das relações de desigualdade, de contradição ou de subordinação que assinalam sua dependência em relação ao "todo complexo com dominante" (Pêcheux, 1975, p. 146) das FDs, (...) e se se chama interdiscurso ao todo complexo com dominante da FD, então é preciso admitir que o estudo de um processo discursivo no seio de uma FD dada não é dissociável do estudo da determinação desse processo discursivo por seu interdiscurso. Isso implica principalmente que a decalagem entre duas FDs, tal que a primeira serve de "matéria prima representacional" (Fuchs e Pêcheux, 1975, p. 13) para a segunda, 
deve ser necessariamente levado em conta em teoria como em análise do discurso... (p. 35)

E acrescenta:

Com efeito, o interdiscurso é o lugar no qual se constituem, para um sujeito falante que produz uma seqüência discursiva dominada por uma FD determinada, os objetos de que esse sujeito enunciador se apropria para fazer deles objetos de seu discurso, ${ }^{10}$ bem como as articulações entre esses objetos, pelos quais o sujeito enunciador vai dar uma coerência a seu propósito. (p. 35)

Ora, pode-se verificar claramente que a forma de incorporação dos préconstruídos não é a mesma segundo se trate, em cada caso, dos elementos de um ou de outro discurso. Ou seja, os termos característicos da FD comunista são retomados, os da FD cristã são precedidos de negativas. Do que resulta, a meu ver, algo que deveria ser claro para esta teoria: que cada FD fornece os elementos a serem por ela retomados, e que a outra FD fornece os elementos a serem recusados pela mesma FD, o que confirmaria o que disse acima, a propósito do processo de contra-identificação. Parece que tanto Pêcheux quanto Courtine fornecem fatos (um, a título de exemplo, outro, com base em um corpus) que põem em cheque suas próprias teses.

10 Aqui, a palavra "discurso" parece significar uma seqüência produzida em determinada circunstância, e não uma FD. 


\section{Em Maingueneau}

Creio que Maingueneau apresenta uma noção de interdiscurso menos pomposa, porém mais operacional e mais produtiva. Segundo ele, "é necessário afinar este termo muito vago para nosso propósito e substitui-lo por uma tríade: universo discursivo, campo discursivo, espaço discursivo" (p. 27). ${ }^{11}$

Por "universo discursivo", o autor entende o conjunto de formações discursivas de todos os tipos que interagem numa conjuntura dada. Este universo discursivo representa necessariamente um conjunto finito, mesmo que não possa ser apreendido em sua globalidade. É de pouca utilidade para o analista e define apenas uma extensão máxima, o horizonte a partir do qual serão construídos domínios susceptíveis de serem estudados, os "campos discursivos". A noção de universo discursivo proposta por Maingueneau recobre, é mais ou menos equivalente, à noção de interdiscurso de Pêcheux.

Por "campo discursivo", Maingueneau entende um conjunto de formações discursivas que se encontram em concorrência, delimitam-se reciprocamente em uma região determinada do universo discursivo, seja em confronto aberto, em aliança, na forma de neutralidade aparente etc. entre discursos que possuem a mesma função social e divergem sobre o modo pelo qual ela deve ser preenchida. Pode tratar-se do campo político, filosófico, dramatúrgico, gramatical etc. Esse recorte em "campos" não define zonas insulares; é apenas uma abstração necessária, que deve permitir abrir múltiplas redes de trocas. Não se trata de delimitações evidentes.

Para o autor, é no interior do campo discursivo que se constitui um discurso, e sua hipótese é que tal constituição pode deixar-se descrever em termos de operações regulares sobre formações discursivas já existentes. O que não significa, entretanto, que os discursos se constituam todos da mesma forma em todos os discursos desse campo; nem é possível determinar a priori as modalidades das relações entre as diversas formações discursivas de um campo.

Finalmente, Maingueneau propõe isolar espaços discursivos, isto é, subconjuntos de formações discursivas cuja relação o analista julga pertinente para seu propósito. Tais restrições devem resultar apenas de hipóteses fundadas sobre um conhecimento dos textos e um saber histórico, que serão em seguida confirmados ou infirmados quando a pesquisa progredir.

11 A exposição de conceitos que se segue é, às vezes, a transcrição quase literal de trechos de Maingueneau (1984, p. 27-30). 
Acrescenta que reconhecer este tipo de primado do interdiscurso é incitar a construir um sistema no qual a definição da rede semântica que circunscreve a especificidade de um discurso coincide com a definição das relações desse discurso com seu Outro. No nível das condições de possibilidade haveria, pois, apenas um espaço de trocas e jamais de identidade fechada. Esse ponto de vista vai de encontro ao que adotam espontaneamente os enunciadores discursivos; esses, longe de admitir esse descentramento radical, reivindicam, de fato, a autonomia de seu discurso.

Essa colocação em causa de uma concepção primária do "fechamento" estrutural inscreve-se no prolongamento de uma corrente da análise do discurso que busca repensar as relações do Mesmo e do Outro tais como se desenhavam nos anos 60. Os procedimentos utilizados nessa época visavam a revelar a identidade a si de cada formação discursiva, graças à construção de núcleos de invariância em torno de alguns pontos privilegiados do discurso. Nesse quadro, a relação com as outras formações discursivas só podia ser pensada segundo o modo espontâneo da justaposição de unidades exteriores umas às outras. $\mathrm{O}$ interdiscurso aparecia como um conjunto de relações entre diversos "intradiscursos" compactos. O que se trata de subverter é essa equivalência entre exterior do discurso e interdiscurso, para pensar a presença do interdiscurso no próprio coração do intradiscurso, o que Courtine chama a "inconsistência de uma formação discursiva, entendida como efeito do interdiscurso enquanto exterior específico de uma formação discursiva no próprio interior dela" (apud Maingueneau, 1984, p. 31).

Assim, o Outro não deve ser pensado como uma espécie de "envelope" do discurso nem um conjunto de citações. No espaço discursivo, o Outro não é nem um fragmento localizável, uma citação, nem uma entidade exterior; nem é necessário que seja localizável por alguma ruptura visível da compacidade do discurso. Ele se encontra na raiz de um Mesmo sempre já descentrado em relação a si próprio, que não é em momento algum passível de ser considerado sob a figura de uma plenitude autônoma. O Outro é o que faz sistematicamente falta a um discurso, é aquela parte de sentido que foi necessário que o discurso sacrificasse para constituir sua identidade.

Disso decorre o caráter essencialmente dialógico de todo enunciado do discurso, a impossibilidade de dissociar a interação dos discursos do funcionamento intradiscursivo. Essa intricação do Mesmo e do Outro rouba à coerência semântica das formações discursivas todo o caráter de "essência", cuja inscrição na história seria assessória; não é dela mesma que a formação discursiva tira o princípio de sua unidade, mas de um conflito regrado. 


\section{O simulacro, um tipo especial}

Há construções cujo efeito é idêntico ao do pré-construído, e que, no entanto, não se encontram no interdiscurso. Ou seja, não pertencem, a rigor, a discurso nenhum. A única explicação para seu aparecimento é um dos efeitos da relação de polêmica, o simulacro. ${ }^{12}$ Dou exemplos.

a) Expressões como o logicismo, o formalismo, a tendência logicistaformalista, o biologismo, correntes em discursos científicos (ou de saber) que privilegiam o social ou o histórico, contra o privilégio do biológico e do formal (que nem sempre andam juntos). Trata-se claramente de simulacros dos projetos que se pretendem formais, ou seja, das correntes que adotam metalinguagens formais, que representam em outras linguagens o(s) sentido(s) das expressões, que postulam um certo aparato biológico (eventualmente inato). Outros exemplos do mesmo tipo são desvio teoricista, psicologismo, economicismo.

Esses "pré-construídos" tem uma origem bem específica. Não são tomados do interdiscurso, no sentido de Pêcheux e de Courtine. Derivam claramente de uma relação de embate entre FDs, ou seja, não são já ditos da mesma natureza dos propostos como exemplos paradigmáticos (a crise do petróleo, o terrorismo etc.). Derivam mais claramente do interdiscurso no sentido mais restrito de espaço discursivo, ou seja, são constitutivamente interdiscursivos, o que quer dizer que só vêm à existência como efeito da polêmica.

Outro exemplo, no mesmo campo. No discurso da GGT não se encontra jamais a afirmação de que "la langue ne peut pas tolérer le flou ou dire deux choses à la fois" (Gadet; Pêcheux, 1981, p. 155). ${ }^{13}$ Em outros termos, este enunciado é um simulacro da tentativa de descrição e de representação formal da ambigüidade, que iguala a teoria descritiva (boa ou ruim, pouco importa) com o sonho de construir uma língua perfeita, projeto absolutamente fora dos propósitos da GGT (embora, eventualmente, as descrições que adota possam até sugerir caminhos para a construção de outras linguagens, ou ela possa

12 Para esta noção, ver Maingueneau (1984, cap. 4).

13 Um "formalista" não vê nenhuma diferença entre o que ele diz e o que está dito aqui. Só achará que o que ele faz é uma descrição explícita - ou duas - do "duplo". 
valer-se dessas linguagens para seu aparato descritivo - assim como Pêcheux valeu-se dos computadores ou Galileu da balança ${ }^{14}$ ). Essas representações formais, do ponto de vista de quem as faz, são apenas descrições (boas ou ruins) daquilo que, poder-se-ia dizer, é o próprio da língua, e que o analista do discurso até chega a "usar", como o fez Courtine com a descrição das estruturas sintáticas clivadas feita por Maurice Gross.

b) O discurso humorístico, notadamente o das piadas, fornece, salvo engano, um exemplo relevante para essa mesma tese. Usualmente, piadas põem em relação dois discursos (dois mundos, segundo Freud, dois scripts, segundo Raskin etc.). Ao contrário do que alguns humoristas gostariam de pensar, os discursos postos em relação (in praesentia ou in absentia) são prévios à piada - o que forneceria munição para teses do tipo "tudo já foi dito" e, alternativamente, para teses de que só nos resta o estilo. ${ }^{15}$ Por exemplo, ao bom discurso sobre escola, ou casamento, ou igreja, opõe-se o mau discurso sobre as mesmas instituições - ambos correntes e sólidos, evidentemente, embora com espaços de circulação diferentes.

Mas há um tipo de piada, que se tornou relativamente popular, nos últimos tempos, que "cria" um discurso, não o retoma. Refiro-me às chamadas piadas de gaúcho. Elas opõem ao estereótipo do gaúcho macho o do gaúcho veado. Ora, este último discurso é novo, no sentido de que ele não tem "corpo" em outro lugar que não seja o discurso humorístico. A meu ver, estas piadas constroem as razões históricas estão por ser investigadas - um discurso "novo", não o retomam de outras e diferentes fontes (pelo menos, não públicas, literárias, folclóricas etc.). Penso que uma forma de compreender o que se passa é a hipótese de que se trata do simulacro do macho. Ou seja, a piada trabalha contra (ia dizer "sobre"...) o discurso do macho, e faz dele uma interpretação que incide sobre o traço mais negativo da macheza: não a pouca valentia, por exemplo, mas a inversão de papéis ou preferências sexuais.

14 O efeito é que são Gadet e Pêcheux que fazem a paródia de Chomsky e não, como eles dizem, Chomsky quem faz a paródia da ambigüidade. É bem verdade que logo se redimem, e eles mesmos reconhecem que Chomksy não pretende tal "depuração" da linguagem.

15 "Vamos ao último traço da experiência de Flaubert, em que a busca do como fazer se reduz ao fazer como" (Schneider, 1985, p. 31). 
c) O terceiro exemplo, tomo-o emprestado de Fiorin (1994). Segundo ele, o discurso militar ligado ao golpe de 64, para desqualificar o discurso de oposição, não combate seu sentido "original", mas seu simulacro. Cita trecho de um pronunciamento de Castelo Branco, no qual aparecem seqüências como "os que almejam implantar o totalitarismo de esquerda" e "exploram o nacionalismo para proteger sua ineficiência" no lugar, respectivamente, de "forças populares de vanguarda" e de "membros da burguesia nacional progressista".

d) $\mathrm{Na}$ véspera da apresentação deste trabalho, em sua conferência de abertura do $5^{\circ}$. CELSUL, José Luiz Fiorin produziu um excelente exemplo, ainda mais complexo do que os que apresentei. Introduzindo a noção de ethos, disse, num certo momento: "Mas isso não é psicologismo..." De onde surge esta palavra, "psicologismo"? Uma hipótese é que Fiorin antecipa o que se poderá dizer de seu discurso, a partir de uma certa $\mathrm{FD}$ - suponhamos que seja a $\mathrm{AD}$ : "mas isso que você diz é psicologismo". Que se classifique um certo discurso como psicologismo se explica pela rejeição, por parte da $\mathrm{AD}$, de fundamentos psicológicos para a explicação de fatos discursivos. O simulacro de "psicologia" é "psicologismo". O que Fiorin fez foi negar antecipadamente o que poderia vir a ser dito a propósito do que ele enunciava. $\mathrm{O}$ exemplo é interessante porque, da posição de que falava Fiorin, ele pode negar antecipadamente o que diria de seu discurso um outro que estivesse em outra posição, sendo que o enunciado negado antecipadamente é um simulacro do que Fiorin está dizendo.

Concluindo, diria que, provavelmente, uma tentativa de comparação entre as versões de Pêcheux e de Maingueneau esbarraria numa espécie de "incomensurabilidade" - que talvez produza simulacros de ambas. Não sei se valeria a pena armar um pandemônio por causa de suas diferenças. As ênfases diversas são notórias. Pêcheux se inscreve na vertente althusseriana - e provavelmente o assujeitamento ao interdiscurso é uma "aplicação" da noção de ideologia em geral e o assujeitamento a uma FD, uma aplicação da noção de ideologias particulares. Maingueneau filia-se de certa forma a Foucault, embora, ao contrário dele, privilegie a "superfície" e sua lingüística seja de preferência uma semântica discursiva.

O que pretendi mostrar foi a necessidade de especificar melhor a natureza de determinados elementos presentes em certo discurso, especialmente na medida em que eles têm a ver com interdiscurso. Pareceu-me, como disse, que os préconstruídos, se derivam diretamente de uma FD (e não do interdiscurso), podem 
ser retomados. Mas quando provêm do interdiscurso, são negados, recusados, ou "postos à distância", exatamente porque não se apresentam como evidentes - como deveria ser um pré-construído. Alternativamente, são construídos por um processo peculiar, a partir da semântica de um discurso específico, que, estando em relação de alteridade (polêmica) com outro, constrói dele certos simulacros. Neste caso, trata-se talvez de pré-construídos que funcionam como pseudo-evidências, na medida em que certas formulações não se encontram, como tais, em nenhum discurso, ao contrário das negadas ou recusadas. Isto é, não são retomadas, não estão disponíveis, devem ser "construídas" na polêmica. Se se quiser dizer que pertencem a uma FD, ter-se-ia que especificar, ainda assim, que sua "origem" deve ser atribuída ao mecanismo que gera o simulacro.

\title{
RESUMO
}

Este trabalho discute aspectos da noção de interdiscurso, com ênfase em aparentes incongruências nas obras de Pêcheux e Courtine, notadamente no que se refere ao tratamento do pré-construído, em especificações propostas por Maingueneau e em uma análise sumária de alguns fatos empíricos.

Palavras-chave: interdiscurso, assujeitamento, simulacro, pré-construído.

\begin{abstract}
This paper discusses aspects of the notion of interdiscourse, emphasizing apparent incongruities in the works of Pêcheux and Courtine. It specially deals with the treatment of the pre-constructed in some specifications proposed by Maingueneau and in a preliminary analysis of some empyrical data.

Key-words: Interdiscourse, simulacrum, pre-constructed, subjecting.
\end{abstract}




\section{REFERÊNCIAS}

BRUNELLI, A. F. Interdiscurso e intertexto no discurso de auto-ajuda. 2001. No Prelo.

CHARAUDEAU, P.; MAINGUENEAU, D. Dictionnaire d'analyse du discours. Paris: Éditions du Seuil, 2002.

COURTINE, J.-J. Analyse du discours politique: le discours communiste adressé aux chrétiens. Langanes 62. Paris: Didier-Larousse, 1981.

FIORIN, J. L. Polifonia textual e discursiva. In: BARROS, D. L. P.; FIORIN, J. L. (Orgs.). Dialogismno, polifonia, intertextualidade. São Paulo: Edusp, 1994. p. 29-36.

GADET, F.; PÊCHEUX, M. La langue introuvable. Paris: Maspero, 1981.

MAINGUENEAU, D. Novas tendências em análise do discurso. Campinas: Pontes/Ed. da Unicamp, 1987.

MIQUELETTI, F. Discurso, tom e caráter: uma análise do ethos tucano. Campinas, 2002. Dissertação (Mestrado) - Instituto de Estudos da Linguagem.

PÊCHEUX, M. Semântica e discurso. Campinas: Ed. da Unicamp, 1975.

SCHNEIDER, M. Ladrões de palavras. Campinas: Ed. da Unicamp, 1985. 